\title{
Beter met een manometer
}

\section{Onderzoek naar gebruik manometer tijdens balloneren van patiënten met ALI of ARDS}

\author{
Roel Smit
}

Sinds een aantal jaren gebruiken IC-verpleegkundigen op de IC in het Antonius Ziekenhuis in Sneek een manometer wanneer zij patiënten met Acute Lung Injury (ALI) of Acute Respiratory Distress Syndrome (ARDS) balloneren (handmatig beademen) met een Watersset. De Watersset met het regelbare expiratieventiel en de aangesloten manometer bieden de mogelijkheid de luchtwegdrukken van de patiënt tijdens het balloneren te sturen en te monitoren. In dit artikel bespreken we de resultaten uit het onderzoek dat op onze afdeling is gedaan naar het gebruik van de manometer.

Patiënten met ALI of ARDS zijn extreem afhankelijk van PEEP (Positive End-Expiratory Pressure). Geheel of gedeeltelijk verlies van deze PEEP kan leiden tot instabiliteit en mogelijk longschade door het collaberen van alveoli. Het is dan ook zeer gewenst deze PEEP continu te waarborgen, ook als de machinale beademing tijdelijk onderbroken wordt en de patiënt handmatig wordt beademd. Tijdens dit balloneren kan echter gemakkelijk een ongewenst verlies van PEEP optreden. Door een manometer te gebruiken tijdens deze handeling, kan dit worden voorkomen. Het balloneren wordt uitgevoerd in een aantal situaties zoals tijdens een bronchiaal toilet, een handmatige recruteermanoeuvre, het wisselen van de slangenset of beademingsmachine of op elk ander moment dat machinale beademing tijdelijk onderbroken is.

Roel Smit $(\bowtie)$

Roel Smit is IC-verpleegkundige, Ventilation Practitioner Intensive Care, Antonius Ziekenhuis Sneek

\section{Daarom een manometer}

Aanleiding voor het gebruik van een manometer tijdens het balloneren (zie kader 1) was het toepassen van het Open Long Concept (OLC).

Het OLC is een beademingsconcept om longen te openen en open te houden en heeft de volgende kenmerken:

1. indicatie: ALI en ARDS

2. longprotectief beademen, het voorkomen van:

3. $\mathrm{O}_{2}$-toxiciteit

4. volutrauma/barotrauma

5. biotrauma

6. atelectrauma (shear-stress)

7. preventie van het geheel of gedeeltelijk wegvallen van de ingestelde PEEP (zie kader 2)

8. recruteermanoeuvres op indicatie (volgens protocol)

9. aangepast bronchiaal toilet (volgens protocol).

In de praktijk wordt een manometer ook gebruikt tijdens het balloneren van beademde patiënten die met een PEEP van $=10 \mathrm{~cm} \mathrm{H}_{2} \mathrm{O}$ beademd worden, maar bij wie de diagnose ALI of ARDS (nog) niet gesteld is.

Kader 1

Vraagstelling Wordt met het gebruik van een manometer tijdens het balloneren een verlies van PEEP voorkomen?

\section{Methode}

Onderzoek naar het balloneren zonder en met manometer in relatie tot een op de beademingsmachine ingestelde PEEP. De deelnemers zijn ICverpleegkundigen.

\section{Resultaten}

1. Tijdens het balloneren zonder manometer wordt in gemiddeld $14 \%$ van de meetwaarden de ingestelde 
PEEP gewaarborgd. Bij de $86 \%$ afwijkende meetwaarden wordt meestal een te lage PEEP gegeven.

2. Tijdens het balloneren met manometer wordt in gemiddeld $87 \%$ van de meetwaarden de ingestelde PEEP gewaarborgd. In de overige 13\% van de meetwaarden wordt een gemiddeld $1 \mathrm{~cm}$ $\mathrm{H}_{2} \mathrm{O}$ te lage PEEP gegeven.

\section{Conclusie}

Met het gebruik van een manometer wordt verlies van PEEP tijdens het balloneren voorkomen.

Kader 2

Wat is PEEP? PEEP wordt gezien als belangrijk onderdeel van de behandeling van beademde patiënten met ALI of ARDS. Positieve effecten van PEEP zijn het stabiliseren van het FRC met als gevolg een afname van de intrapulmonale rechts-links shunt en een betere arteriële oxygenatie. PEEP verhoogt de gemiddelde luchtwegdruk, redistribueert extravasculair longwater en voorkomt longoedeem. De 'beste' PEEP heeft een optimale (juiste) hoogte en heeft dan veel positieve effecten en weinig of geen nadelige effecten. Over de optimale PEEP-hoogte is na vele jaren van onderzoek nog steeds geen consensus. ${ }^{1}$ Te hoge PEEP kan een negatieve invloed hebben op de hemodynamiek, de dode-ruimte ventilatie in de long vergroten of mogelijk zelfs bijdragen aan het ontstaan van longschade veroorzaakt door overdistentie van gezonde longdelen..$^{2-3}$

Te lage PEEP wordt geassocieerd met het ontstaan van ongewenste processen in de longen van patiënten met ALI of ARDS: longcollaps, derecrutering, collaberen van alveoli, eind-expiratoire collaps van longdelen, ontstaan van instabiele alveoli en verlies van surfactant. Deze processen kunnen het cyclisch openen en sluiten van alveoli doen ontstaan of verergeren wat longschade of zelfs mogelijk systemische schade tot gevolg kan hebben door shearstress en het vrijkomen van schadelijke stoffen. ${ }^{4-9}$ Een optimale PEEP kan ongewenste processen als het collaberen van alveoli voorkomen, daarmee een open long in stand houden en daardoor beschermen tegen VALI. ${ }^{10-15}$ Consensus over de optimale PEEP bestaat (nog) niet, toch zal in de praktijk een PEEPniveau gekozen worden dat voor de betreffende patiënt als de 'beste' PEEP gezien wordt. Geheel of gedeeltelijk verlies hiervan is zeer onwenselijk.

\section{Het onderzoek}

Het onderzoek vond plaats op een algemene IC-afdeling in een perifeer ziekenhuis met 5 beademingsbedden. De deelnemers aan het onderzoek waren 22 IC- verpleegkundigen. Zij werkten hieraan mee door in een proefopstelling met een kunstlong en in een praktijksituatie zonder en met een manometer te balloneren.

\section{Bevindingen}

De gebruikte methode bestond uit het uitvoeren van vergelijkend en beschrijvend onderzoek in een proefopstelling en in een praktijksituatie naar het balloneren zonder en met manometer in relatie tot een op de beademingsmachine ingestelde PEEP. Bij het verwerken van de meetgegevens is een afwijking van $1 \mathrm{~cm} \mathrm{H}_{2} \mathrm{O}$ naar boven en naar beneden getolereerd.

De proefopstelling: in twee situaties met PEEP-hoogtes van 10 en $16 \mathrm{~cm} \mathrm{H}_{2} \mathrm{O}$ werden 22 IC-verpleegkundigen gevraagd tijdens het balloneren van een kunstlong de PEEP te waarborgen zonder en met manometer. Voorafgaand werd de kunstlong beademd door een Evita-4beademingsmachine. $\mathrm{Na}$ een 'inspiration hold'manoeuvre werd de tube tijdelijk afgeklemd en aangesloten op een Watersset, waarna het balloneren werd gestart. Tegelijk werd gestart met het meten van de handmatig gegeven PEEP.

De praktijksituatie: in een praktijksituatie werden tien ICverpleegkundigen gevraagd om met het gebruik van een manometer tijdens het balloneren bij een beademde patiënt $14 \mathrm{~cm} \mathrm{H}_{2} \mathrm{O}$ PEEP te waarborgen.

\section{Resultaten}

Dit betekent het volgende:

1. Zonder het gebruik van een manometer vindt een substantieel verlies van PEEP plaats tijdens het balloneren in een proefopstelling.

2. Met het gebruik van een manometer kan een verlies van PEEP tijdens het balloneren in een proefopstelling en in een praktijksituatie voorkomen worden.

3. Bij het balloneren in een praktijksituatie is $11 \%$ van de meetwaarden gemiddeld $8 \%$ te laag. Dit is acceptabel maar dient toch te leiden tot een nog grotere alertheid

\begin{tabular}{|c|c|c|}
\hline $\begin{array}{l}\text { Ballone } \\
=10 \text { en }\end{array}$ & $\begin{array}{l}\text { in twee pro } \\
5 \mathrm{~cm} \mathrm{H} 2 \mathrm{O}\end{array}$ & stellingen ZONDER manometer: EEP \\
\hline & Percentage & $\begin{array}{c}\text { Gemiddeld te hoog of te laag gegeven } \\
\text { PEEP }\end{array}$ \\
\hline $\begin{array}{l}\mathrm{Te} \\
\text { hoog }\end{array}$ & $35.5 \%$ & $6 \mathrm{~cm} \mathrm{H}_{2} \mathrm{O}$ \\
\hline Goed & $14 \%$ & - \\
\hline Te laag & $50.5 \%$ & $4.4 \mathrm{~cm} \mathrm{H}_{2} \mathrm{O}$ \\
\hline
\end{tabular}


Balloneren in twee proefopstellingen MET manometer:

waarborgen PEEP $=10$ en $16 \mathrm{~cm} \mathrm{H}_{2} \mathrm{O}$

Percentage Gemiddeld te hoog of te laag gegeven PEEP

$$
1.2 \mathrm{~cm} \mathrm{H}_{2} \mathrm{O}
$$

Te

$$
2 \%
$$$$
83 \%
$$

Goed

$83 \%$

Te laag

$15 \%$

$1 \mathrm{~cm} \mathrm{H}_{2} \mathrm{O}$

ten aanzien van het waarborgen van de PEEP tijdens het balloneren.

Uit bovenstaande blijkt dat met het gebruik van een manometer verlies van PEEP tijdens het balloneren wordt voorkomen. Bij patiënten met ALI of ARDS is er daardoor tijdens deze handeling minder kans op het collaberen van alveoli.

\section{Afronding}

Het openen en open houden van de long bij beademde patiënten met ALI of ARDS blijft een onderwerp waar nationaal en internationaal grote aandacht voor is. De hoofddoelen daarbij zijn een voldoende gaswisseling en het voorkomen van Ventilator Associated Lung Injury (VALI). PEEP wordt gezien als een belangrijk onderdeel van deze strategie. Verlies van PEEP bij patiënten met ALI of ARDS moet en kan voorkomen worden. ICverpleegkundigen leveren hieraan een belangrijke bijdrage door preventieve maatregelen te nemen: het gebruik van een gesloten uitzuigsysteem, het voorkomen van disconnecties in het beademingscircuit of, indien dit toch noodzakelijk is, het tijdelijk afklemmen van de tube. Het gebruik van een manometer tijdens balloneren is een belangrijke aanvullende maatregel om verlies van PEEP te voorkomen.

Bij patiënten met ALI of ARDS wordt in literatuur een verlies van PEEP geassocieerd met het collaberen van alveoli. In deze studie is aannemelijk gemaakt dat met het gebruik van een manometer een verlies van PEEP tijdens balloneren voorkomen kan worden. Het expiratieventiel

\begin{tabular}{|c|c|c|}
\hline \multicolumn{3}{|c|}{$\begin{array}{l}\text { Balloneren in praktijkopstelling MET manometer: waarborgen } \\
\text { PEEP }=14 \mathrm{~cm} \mathrm{H} \mathrm{H}_{2} \mathrm{O}\end{array}$} \\
\hline & Percentage & $\begin{array}{c}\text { Gemiddeld te hoog of te laag gegeven } \\
\text { PEEP }\end{array}$ \\
\hline $\begin{array}{l}\text { Te } \\
\text { hoog }\end{array}$ & $13 \%$ & $1.3 \mathrm{~cm} \mathrm{H}_{2} \mathrm{O}$ \\
\hline Goed & $76 \%$ & - \\
\hline Te laag & $11 \%$ & $\mathrm{~cm} \mathrm{H}_{2} \mathrm{O}$ \\
\hline
\end{tabular}
van een Watersset geeft de mogelijkheid tijdens het
Verklarende woordenlijst

Atelectrauma:

schade aan longweefsel door het telkens openen en sluiten van alveoli

Balloneren:

het handmatig overnemen of ondersteunen van de ademhaling van een invasief beademde patiënt met behulp van een Watersset, met als leidraad de bij de patiënt op de machine ingestelde frequentie, I:E-ratio en slagvolume. Balloneren wordt in dit artikel niet gelijk gesteld aan bronchiaal toilet, of aan manuele hyperinfl atie. Dit laatste suggereert het geven van grote(re) slagvolumes, wat niet wenselijk wordt geacht bij patiënten met ALI of ARDS.

Barotrauma: schade aan longweefsel door hoge beademingsdrukken

Biotrauma: schade aan longen en aan andere organen door het vrijkomen van ontstekingsmediatoren

Recruteermanoeuvre: het met hogere drukken openen en openhouden van longdelen

Volutrauma: schade aan longweefsel door grote slagvolumes

balloneren de gegeven PEEP te sturen, een manometer geeft de mogelijkheid de gegeven PEEP te monitoren.

\section{Aanbevelingen}

Naar aanleiding van deze studie en de daaruit voortkomende resultaten doen we graag de volgende aanbevelingen:

1. Gebruik een manometer tijdens het balloneren van patiënten met ALI of ARDS of patiënten met een risico op het ontwikkelen ervan.

2. Gebruik een manometer tijdens het balloneren van elke beademde patiënt (vanuit het oogpunt van kwaliteit en veiligheid).

3. Train IC-teams in het gebruik van een manometer tijdens het balloneren van beademde patiënten.

\section{Literatuur}

Slutsky AS, Hudson LD. PEEP or No PEEP - Lung Recruitment May Be the Solution. N Engl J Med;354:1839-41, 2006.

The ARDS-Network. Higher versus Lower Positive End-Expiratory Pressures in Patients with the Acute Respiratory Distress Syndrome. N Engl J Med;351:327-36, 2004.

Gattinoni L et al. Lung Recruitment in Patients with the Acute Respiratory Distress Syndrome. N Engl J Med;354:1775-86, 2006.

Lachmann B. Open up the lung and keep the lung open. Intensive Care Med;18:319-321, 1992. 
Cereda $\mathrm{M}$ et al. Positive end-expiratory pressure prevents the loss of respiratory compliance during low tidal volume ventilation in acute lung injury patients. Chest;109:480-485, 1996.

Ranieri VM et al. Effect of Mechanical Ventilation on Infl ammatory Mediators in Patients with Acute Respiratory Distress Syndrome. J American Medical Association; 282:54-61, 1999.

Maggiore SM et al. Alveolar Derecruitment at Decremental Positive End-Expiratory Pressure Levels in Acute Lung Injury. Am J Respir Crit Care Med Vol 164. pp 795-801, 2001.

Halter JM et al. Positive End-Expiratory Pressure after a Recruitment Maneuver Prevents Both Alveolar Collapse and Recruitment/Derecruit ment. Am J Respir Crit Care Med Vol 167. pp 1620-1626, 2003.

Moloney ED and Griffi ths MJD. Protective ventilation of patients with acute respiratory distress syndrome. $\mathrm{Br} \mathrm{J}$ Anaesth; 92:261-70, 2004

American Thoracic Society. International Consensus Conferences in Intensive Care Medicine: Ventilator-associated Lung Injury in ARDS. Am J Respir Crit Care Med;160. pp 2118-2124, 1999.

Amato $\mathrm{M}$ et al. Effect of a protective-ventilation strategy on mortality in the acute respiratory distress syndrome. N Engl $\mathrm{J}$ Med;338:347-54, 1998.

The ARDS-Network. Ventilation With Lower Tidal Volumes As Compared With Traditional Tidal Volumes For Acute Lung Injury and The Acute Respiratory Distress Syndrome. N Engl J Med;342:1301-8, 2000.

Gattinoni L et al. What Has Computed Tomography Taught Us about the Acute Respiratory Distress Syndrome? Am J Respir Crit Care Med Vol 164. pp 1701-1711, 2001.

Richard JC et al. Infl uence of Tidal Volume on Alveolar Recruitment. Am J Respir Crit Care Med Vol 163. pp 1609-1613, 2001.

Cosimini $\mathrm{P}$ et al. Ventilatory mechanics and the application of positive endexpiratory pressure. European Respiratory J; Volume 7(20):181-194, 2002. 